\title{
Effects of givenness and constraints on free word order
}

\author{
Stavros Skopeteas and Gisbert Fanselow
}

Linguistics Department, University of Potsdam

\section{Word order and givenness ${ }^{1}$}

Clark \& Clark (1977) and Clark \& Haviland (1977) have proposed that constituent order is influenced by a principle requiring that given information precede new information in a sentence ( $\succ \succ N$-principle) (see also Hörnig and Weskott, this volume). The importance of this principle for linearization in the world's languages has been established in quite a number of studies, see, e.g., Siewierska (1993). Given elements come to precede new material by various mechanisms. Some languages use a simple reordering rule (scrambling) for having linear order conform with the $\mathrm{G} \succ \mathrm{N}$-principle, while others take recourse to passivization (A-movement in the sense of Chomsky 1981), apparently because of a general lack of constituent order flexibility (see Mathesius 1975:156ff., Tomlin 1995:538, Prat Sala 1997:99). Other givenness effects come about by the choice of different constructions that are not syntactically related to each other. For example, the $\mathrm{G} \succ \mathrm{N}$-principle affects the choice among the double object and the NP PP construction for English verbs with two objects (Collins 1995). Following Oehrle (1976), many have argued for a purely lexical relation between the two constructional options of give and similar verbs. Likewise, givenness influences the order of structural adjuncts in German, but since adjuncts do not scramble (Haider \& Rosengren 2003), given before new order is base-generated in this domain.

\footnotetext{
${ }^{1}$ This paper evolved within the project D2 "Typology of Information Structure" in the SFB 632 "Information Structure" (University of Potsdam/Humboldt University Berlin, financed by the DFG). We want to thank Caroline Féry, Hubert Haider, Sam Hellmuth, Robin Hörnig, Ivona Kučerova, and Malte Zimmermann for helpful comments. Special thanks are due to Rusudan Asatiani, Shorena Bartaia, Tamar Khizanishvili, and Tamar Kvaskhvadze for consulting us about the syntactic and information structural properties of Georgian.
} 
The present paper is concerned with such syntactic mechanisms that allow given material to precede new information. We present the results of an elicitation experiment investigating the syntactic reflexes of givenness in twelve languages. Particular attention is paid to German and Georgian, but our perspective is broadened by the results for American English, Czech, Dutch, Canadian French, Greek, Hungarian, Konkani, Yucatec Maya, Prinmi, and Teribe. Deviations from normal word order turn out to be licensed in all but one (Greek) of these languages in the interest of respecting the $\mathrm{G} \succ \mathrm{N}$ principle. ${ }^{2}$ Given objects are fronted by A-movement (Chomsky 1981). Languages differ as to whether they employ simple A-scrambling (Déprez 1989, Mahajan 1990) or change grammatical functions in order to move a given XP leftwards. The former option seems preferred when available, but German fails to make use of its structural potential here.

$\mathrm{A}^{\prime}$-movement in the sense of Chomsky (1981) is normally not used as a syntactic reflex of givenness. That $\mathrm{A}^{\prime}$-movement is unavailable for this purpose is not unexpected. After all, $\mathrm{A}^{\prime}$-movement displaces operators (such as wh-phrases), and 'givenness' is not a concept corresponding to a semantic operator. ${ }^{3}$ The absence of a syntactic reflex of givenness in Greek may be due to the fact that the (relevant) syntactic inventory of Greek consists of $\mathrm{A}^{\prime}$-movement operations only, which are useless for the expression of givenness. When we observe that Hungarian nevertheless places given phrases into $\mathrm{A}^{\prime}$-positions, this suggests that they are not connected to operator status here, as assumed by Kiss (2003).

\section{Givenness and word order: an elicitation experiment}

The experiment presented here is part of QUIS, a tool for linguistic fieldwork created by the SFB 632 (University of Potsdam/Humboldt University Berlin, see Skopeteas et al. 2006). In the present study, the participants were asked to describe a sequence of two scenes presented in pictures. In the first scene, an individual, e.g., 'a boy', was introduced. In the second scene, this individual was involved in an event which is likely to be encoded by a transitive verb with two arguments, e.g. 'the boy is kicking a man on the shoulders'. One of the verb's arguments is thus given information, the other, new

\footnotetext{
${ }^{2}$ See Krifka (2007) for an overview of the devices used for indicating givenness.

${ }^{3}$ See Kučerova (2007) for a different view. A discussion of her proposal is beyond the scope of the present paper.
} 
information. The critical description concerns the second scene (henceforth, 'target scene'). The information structure of this description depends on the first scene (henceforth, 'context scene') introducing either the agent or the patient, as shown in the experimental conditions in (1).

(1) ag/giv: $\quad$ (=agent/given \& patient/new)

At the time of the target description, the agent (and not the patient) is part of the given information.

pat/giv: $\quad$ (=agent/new \& patient/given)

At the time of the target description, the patient (and not the agent) is part of the given information

In natural discourses, the constellation 'ag/giv \& pat/new' is the most frequent contextual situation, while 'ag/new \& pat/giv' occurs less frequently (Du Bois 2003:34ff.). A comparison of this pair of contexts should reveal whether there is a preference for given information to precede new information. For languages in which agents precede patients in canonical word order, canonical word order and $\mathrm{G} \succ \mathrm{N}$ order are harmonically aligned in the condition 'ag/giv \& pat/new', while they are in conflict in the condition 'ag/new \& pat/giv'.

The two conditions concerning givenness were implemented as follows. A total of 8 sets of twopicture sequences was constructed, involving 8 different events with an agent and a patient. Each informant has been confronted with the conditions in (1) twice (the further items related to further experimental conditions, see Skopeteas et al. 2006 for details). Since we are interested in the effect of givenness on the linear arrangement of subjects and objects, only those reactions of the participants entered our analysis which consisted of clauses with an agent and a patient. Reactions to the stimuli that did not meet this requirement were excluded from further analysis. Furthermore, in languages with a determiner system such as German, the choice of an (in-) definite determiner in an NP indicates whether the participant's response conformed with the intended distribution of givenness among agent and patient. When both arguments of the target scene were referred to by indefinite NPs, this suggests that the participant did not recognize the intended referential identity of one of the arguments of the target scene with the referent introduced in the context scene. Similarly, when both arguments were expressed by definite NPs, this suggests that the participant may have assumed that the referents of 
both arguments are included in the situational common ground (perhaps taking into account that the instructor knows the pictures). In both cases, the response does not meet critical assumptions about the common ground. For this reason, such data has also not entered our analysis.

\section{The object fronting strategy}

Six languages in our sample simply front the object in contexts in which the patient is given and the agent new: Georgian, Czech, Hungarian, Konkani, Prinmi, and Teribe.

\subsection{Georgian}

Georgian speakers produced four different word orders in our data set: ${ }^{4}$ SOV (2a), SVO (2b), OSV (2c), and OVS (2d).

(2) (a) [sc-1] 'A man is walking...'

$$
\begin{aligned}
& \text { [sc-2] k'ac-i kal-s e-kač-eb-a } \\
& \text { man-NOM woman-DAT (IO.3)OV-move.up-THM-PRS.S.3.SG }
\end{aligned}
$$

(b) [sc-1] 'A man is standing...'

$$
\begin{array}{lll}
\text { [sc-2] } & \ldots \text { k'ac-i } \quad \text { u-rt'q-am-s } & \text { kal-s. } \\
\text { man-NOM } \quad \text { (IO.3)OV-hit-THM-PRS.S.3.SG } & \text { woman-DAT } \\
\text { '...the man is hitting the woman.' } & \\
\text { ('ag=sbj/first'; condition 'ag/giv') } &
\end{array}
$$

(c) [sc-1] 'There is a box on the table...'

$$
\begin{aligned}
& \text { [sc-2] ... qut-s k'ac-i a-gd-eb-s } \\
& \text { box-DAT man-NOM NV-(IO.3)throw-THM-PRS.S.3.SG } \\
& \text { '...a man is throwing the box.' } \\
& \text { ('ag=sbj/non-first'; condition 'pat/giv') }
\end{aligned}
$$

(d) [sc-1] 'The boy is standing on the stairs...'

\footnotetext{
${ }^{4} 32$ native speakers of Georgian, students at the University of Tbilisi, were interviewed in Tbilisi (Georgia) in October 2005 and January 2006. Experimental sessions were conducted by Stavros Skopeteas (October 2005) and Rusudan Asatiani (January 2006) and transcribed by Rusudan Asatiani, Shorena Bartaia, and Nutsa Tsetereli.
} 


$$
\begin{aligned}
& \text { [sc-2] ... bitf'-s a-gd-eb-s gogo k'ib-i-dan. } \\
& \text { boy-DAT NV-(IO.3)throw-THM-PRS.S.3.SG girl(NOM) stair-INS-from } \\
& \text { '...a girl is throwing the boy from the stairs.' } \\
& \text { ('ag=sbj/non-first'; condition 'pat/giv') }
\end{aligned}
$$

All descriptions obtained in the condition 'ag/giv' are canonical active clauses ('ag=sbj/first') with the agent preceding the patient (see Table 1). This result was expected, since the preference for given information to precede new information is in accordance with the canonical word order in this condition. The condition 'pat/giv' involves a conflict between the preference for agents to precede patients and the $\mathrm{G} \succ \mathrm{N}$ principle. As an effect of this conflict, we find active clauses with non-canonical word order ('ag=sbj/non-first'), in addition to sentences with canonical order. ${ }^{5}$ The effect of givenness on word order thus manifests itself in a significant difference in the percentage of non-canonical active sentences in which patients precede agents between the condition 'ag/giv' $(0 \%)$ and the condition 'pat/giv' $(39.2 \%)\left(t_{23}=3.99, p<.05\right){ }^{6}$

\footnotetext{
${ }^{5}$ The word order change in the given-patient condition is optional in all the languages we have investigated. This could mean that there is no grammatically unique solution to the conflict between the ordering principles agent > patient and given > new. The gradient nature of the givenness effect might also indicate that givenness triggers word order changes only in combination with further factors not controlled in the experiment, so that the experimental design was not strong enough to always yield a givenness effect.

${ }^{6}$ In the condition 'ag/giv \& pat/new', 3 of 42 agent expressions (7.1\%) are pronominal. In the condition 'ag/new \& pat/giv', two of the clauses with a given patient (with OVS and SVO order, respectively) involved a pronominal object (2 of 51 clauses, i.e. 3.9\%). In the condition 'ag/giv \& pat/new', 33 out of 42 clauses are V-medial (78.5\%), the others V-final. In the condition 'ag/new \& pat/giv', 25 out of 31 clauses with an initial agent (80.6\%) and 9 out of 20 clauses with an initial patient (45\%) are V-medial. We do not assume an effect of givenness on V position. See below for a brief discussion of the related structural facts.
} 


\begin{tabular}{|c|c|c|c|c|}
\hline & \multicolumn{4}{|c|}{ Georgian } \\
\hline & \multicolumn{2}{|c|}{ ag/giv } & \multicolumn{2}{|c|}{ pat/giv } \\
\hline & $n$ & $\%$ & $n$ & $\%$ \\
\hline total & 64 & & 64 & \\
\hline other & 22 & & 13 & \\
\hline $\mathrm{ag}=\mathrm{sbj} /$ first & 42 & 100 & 31 & 60.8 \\
\hline $\mathrm{ag}=\mathrm{sbj} /$ non-first & - & - & 20 & 39.2 \\
\hline $\mathrm{ag}=$ non $-\mathrm{sbj} /$ non-first & - & - & - & - \\
\hline $\mathrm{ag}=$ non$-\mathrm{sbj} /$ first & - & - & - & - \\
\hline
\end{tabular}

A brief consideration of the grammatical system of Georgian suggests that the simple reordering observed in our experiment has been effected by A-movement. There is ample evidence for an asymmetrical relation between the verbal arguments, with the subject c-commanding the object in base order (cf. Amiridze 2006, Anderson 1984, Boeder 1989, Harris 1981, Joppen-Hellwig 2001). The behavior of the target position of movement with respect to argumental binding belongs to the clear diagnostics for the movement type (see Deprez 1989, Mahajan 1990). When the landing site is an A-position, new binding relations can be entered after movement. $A^{\prime}$-movement, however, does not create new binding options. For Georgian, the creation of new binding possibilities in the context of object preposing has been documented by McGinnis (2004).

Next to the binding properties, the availability of movement of a constituent across (embedded) clause boundaries is often assumed to be a diagnostics for $\mathrm{A}^{\prime}$-movement. The absence of such long-distance dependencies suggests that the movement operation is of the A-type (but such a conclusion is not inevitable, see Müller \& Sternefeld 1994). The following examples from Georgian show that long distance scrambling is not possible. (3a) illustrates the canonical construction containing a matrix and a subordinated clause. A long-distance dependency is grammatical in (3c) only, i.e. only in the context of wh-movement, which is a case of $\mathrm{A}^{\prime}$-movement. $\mathrm{O} \succ \mathrm{S}$ order in simple reordering is thus created by A-movement in Georgian.

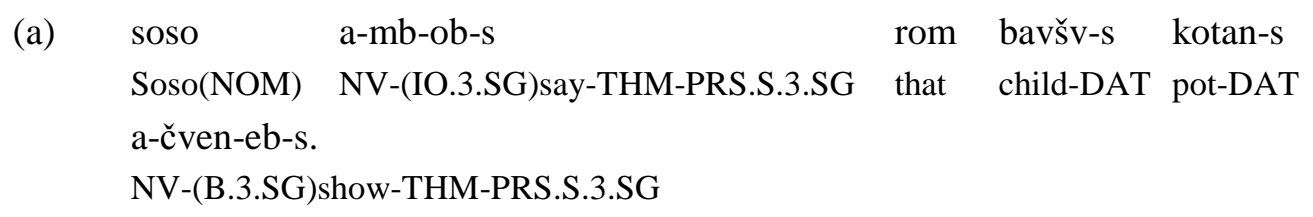

'Soso says that he shows the pot to the child.' 
(b)

\begin{tabular}{|c|c|c|c|c|}
\hline *kotan-s & a-mb-ob-s & Soso & rom & bavšv-s \\
\hline pot-DAT & NV-(IO.3.SG)say-THM-PRS.S.3.SG & Soso(NOM) & that & child-DAT \\
\hline
\end{tabular}

(c)

$\begin{array}{lllll}\text { ra-s } \quad \begin{array}{l}\text { a-mb-ob-s } \\ \text { Nhat-DAT }\end{array} & \text { NV-(IO.3.SG)say-THM-PRS.S.3.SG } & \text { Soso(NOM) } & \text { that } & \begin{array}{l}\text { bav̌̌v-s } \\ \text { child-DAT }\end{array} \\ \text { a-čven-eb-s? } & & & \\ \text { NV-(IO.3.SG)show-THM-PRS.S.3.SG } & & \end{array}$

'What does Soso say that he is showing (it) to the child.'

Georgian speakers never used passive voice in sentences with given objects. Georgian verbs form passive voice by affixation and show all irregularities of morphological passives such as defective verbs, deponent verbs, etc. (see Aronson 1994, Harris 1981, Hewitt 1995). Passive diathesis, which implies promotion of the patient to subject and demotion of the agent to adjunct status, is possible in Georgian, but it only occurs in written styles and is rare. Ivanishvili and Soselia (1999) extracted more than one thousand sentences including a passive verb from Georgian short stories and found only about 20 sentences which can be analyzed as involving verbal diathesis. Passive morphology, rather, shows up with deponent verbs and is used to express potentiality, deliberation, inchoation, etc. Native speakers report that though they could productively form passives, also in the contexts presented in our production study, they would never do it in this context because passive belongs to a formal register.

Object preposing may, but need not be, accompanied by a change in verb position, as observed above (see Skopeteas \& Fanselow 2008 for detailed discussion). Skopeteas \& Fanselow (2008) argue that the base order is SOV and that V medial orders result through an optional V fronting operation. ${ }^{7}$ The medial placement of the verb then allows an analysis similar to the one for German, in which the verb moves to a higher functional head position. If we want to maintain that object preposing involves Amovement in Georgian in the case of given objects, the following analysis comes to mind: the object is first scrambled across the subject (= A-movement), and then it undergoes a purely formal, non-

\footnotetext{
${ }^{7}$ See also Skopeteas, Féry and Asatiani (2009) for evidence from a rating experiment.
} 
operator movement to the position preceding the verb, as sketched in (4) (see similar proposals for German in Frey 2004 and Fanselow 2003).

$$
\text { [FP Object [F Verb [ } \left.\mathrm{t}_{\text {object }} \text { subject }\left[\mathrm{t}_{\text {object }} \mathrm{t}_{\text {verb }}\right]\right] \text { ] ] }
$$

This analysis is supported by the observation that the ability of scrambled phrases to establish new possibilities for binding holds independently of the position of the $\mathrm{V}$, i.e. the observations made above for SOV and OSV order also hold for SVO/OVS order as shown in the following examples:

(a) quela avtor- $\mathrm{i}_{i} \quad$ a-gd-eb-s

every(NOM/DAT) author-NOM NV-(IO.3)throw-THM-PRS.S.3.SG

tav-i-s $\mathrm{s}_{i} \quad$ c'ign-s.

RFL-GEN-DAT book-DAT

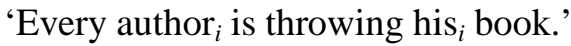

(b) $*$ tav-is-i $\mathrm{i}_{i} \quad$ avtor-i a-gd-eb-s

RFL-GEN-NOM author-NOM NV-(IO.3)throw-THM-PRS.S.3.SG

quela c'ign-s

every(NOM/DAT) book-DAT

(intended) 'His ${ }_{i}$ author is throwing every book , '

(c) quela c'ign-s $s_{i}$ a-gd-eb-s

every(NOM/DAT) book-DAT NV-(IO.3)throw-THM-PRS.S.3.SG

tav-is-i ${ }_{i} \quad$ avtor-i.

RFL-GEN-NOM author-NOM

'His ${ }_{i}$ author is throwing every book ${ }_{i}$ ',

\subsection{Further languages 8}

Czech is known for its word order freedom and uses simple reordering of the clausal constituents in cases in which English uses passive voice (see Mathesius 1975:156ff.). The absence of weak crossover effects suggests that OS orders are derived by A-movement. OS orders in Czech create new binding relations (see Kučerová 2007:139). (6a) exemplifies the canonical SVO word order, elicited in the condition 'ag/giv'. The further examples illustrate two responses to the condition 'pat/giv': a sentence involving OVS order in (6b) and a sentence involving passivization in (6c) (see proportions in Table 2). The dominant strategy in the condition 'pat/giv' is reordering, though a few passive sentences were

\footnotetext{
${ }^{8}$ If not otherwise indicated, the further data sets have been collected with 8 native speakers ( 2 descriptions per condition).
} 
produced as well. ${ }^{9}$ The percentage of patient-first sentences in this condition differs significantly from the non-occurrence of patient first sentences in the condition 'ag/giv' (paired samples $t$-test: $t_{11}=4.06$, $p<.05) .{ }^{10}$
(a) $[\mathrm{sc}-1]$
\{A woman stands in the room.
[sc-2]
Žena uhodila muže woman:NOM hit:PAST:F man.ACC which.M.NOM to her:DAT stojí zády.
stand:3.SG backwards

'The woman hit the man that was standing with his back side towards her.' (ag/giv)

(b) $[\mathrm{sc}-1] \quad$ A chain is lying on the ground. $\}$

[sc-2] a ten řetízek bere pes do tlamy. and the:ACC chain:ACC take:3.SG dog:NOM in mouth:GEN '... and a dog takes the chain in his mouth.' (pat/giv)

(c) $[\mathrm{sc}-1] \quad\{$ There is a woman that is starting to walk on the street. $\}$

$\begin{array}{lllll}\text { [sc-2] } & \text { a je } \quad \text { napadena } & \text { cizím } & \text { mužem ... } \\ & \text { and be:3.SG } & \text { attack:PASS.PTCP:F } & \text { strange:INS } & \text { man:INS } \\ & \text { 'and is attacked by a strange man.' (pat/giv) } & \end{array}$

Table 2: Czech data ${ }^{11}$

\begin{tabular}{|c|c|c|c|c|}
\hline & \multicolumn{2}{|c|}{ ag/giv } & \multicolumn{2}{|c|}{ ag/new } \\
\hline & $\mathrm{n}$ & $\%$ & $\mathrm{n}$ & $\%$ \\
\hline total & 64 & & 64 & \\
\hline other & 19 & & 38 & \\
\hline $\mathrm{ag}=\mathrm{sbj} /$ first & 45 & 100 & 15 & 57.7 \\
\hline $\mathrm{ag}=\mathrm{sbj} /$ non-first & - & - & 9 & 34.6 \\
\hline $\mathrm{ag}=$ non $-\mathrm{sbj} /$ non-first & - & - & 2 & 7.7 \\
\hline $\mathrm{ag}=$ non-sbj/first & - & - & - & - \\
\hline
\end{tabular}

\footnotetext{
${ }^{9}$ Benz (2008) reports a similar result for Russian. In a data set obtained by the same experimental procedure and material, Russian speakers $(n=8)$ produced only canonical active sentences in the condition 'ag/giv \& pat/new' (30 valid sentences), and 3 active sentences involving OVS order (out of 29 valid sentences) in the condition 'ag/new \& pat/giv'.

${ }^{10}$ The obtained frequencies were normalized through the arcsine-square root transformation in order to meet the normality requirements of parametric tests. All probabilities reported in this paper are calculated through one-tailed paired samples $t$-tests. We adopt $p<.05$ as significance level for all data sets.

${ }^{11}$ The data was collected in Leipzig (Germany, January 2008) and transcribed by Denisa Lenertová. 16 native speakers of Czech participated and provided four data points per condition.
} 
The choice of a marked OS order for given objects is thus not mandatory in Czech (in contrast to claims made in Kučerová 2007). Passivization competes with scrambling in the expression of givenness.

Konkani (Goa, India; Southern Indo-Aryan) is an SOV language. There are no syntactic analyses of word order alternation in Konkani, but scrambling is a wide-spread property of Indo-Aryan languages (see Mahajan 1990, Kidwai 2000 for Hindi-Urdu). Konkani lacks an active/passive distinction and morphological means of encoding topics. Our data shows a pattern similar to other V-final languages: when the subject is given, speakers produce only canonical sentences (see 7a); when the object is given, it optionally scrambles over the subject resulting in OSV word order (see illustration in $7 \mathrm{~b}$ and proportions in Table 3). The difference of the means of proportions of OS orders in the two conditions is significant (paired samples $t$-test: $t_{5}=3.4, p<.05$ ).

(a) [sc-1] $\quad$ [Here a man is standing near a slide. $\}$

[sc-2] Hanga to daadlo slide-acher ek rath dukhal-ta. here that man slide-OBL.LOC a tire push-PRS.3.SG

'Here that man is pushing a tire on the slide.' (ag/giv)

(b) $[\mathrm{sc}-1] \quad$ There is a snake here. $\}$

[sc-2] Atan te sarop-a-che shempden sunen ghaans mara-ta.

now that snake-OBL-POS tail dog bite hit-PRS.3.SG

'Now a dog is biting the tail of that snake.' (pat/giv)

Table 3: Konkani data ${ }^{12}$

\begin{tabular}{|c|c|c|c|c|}
\hline & \multicolumn{2}{|c|}{ ag/giv } & \multicolumn{2}{|c|}{ ag/new } \\
\hline & $n$ & $\%$ & $n$ & $\%$ \\
\hline total & 16 & & 16 & \\
\hline other & 5 & & 6 & \\
\hline ag=sbj/first & 11 & 100 & 5 & 50 \\
\hline $\mathrm{ag}=\mathrm{sbj} /$ non - first & - & - & 5 & 50 \\
\hline $\mathrm{ag}=$ non-sbj/non-first & - & - & - & - \\
\hline $\mathrm{ag}=$ non-sbj/first & - & - & - & - \\
\hline
\end{tabular}

The Konkani data are reminiscent of Hindi, Sinhala, and Tamil (see Herring \& Paolillo 1995, cited after Morimoto 2000) in that given objects can, but need not be, placed in front of new subjects. Hindi and Sinhala have (obligatory) indefinite determiners and Hindi can mark definiteness by a definite determiner; the same seems to be true of Konkani.

\footnotetext{
${ }^{12}$ The Konkani data presented here was collected (in Panaji, India, May 2005) and transcribed by Caroline Menezes.
} 
Teribe (Panama/Costa Rica; Chibchan) is a further V-final language which, however, differs from Georgian and Konkani in not allowing OSV word order. Objects always occur left adjacent to the verb; adverbs and non-argument NPs are realized postverbally. Teribe has a direct/inverse voice alternation which does not affect the grammatical status of the arguments (see Quesada 2000, Quesada \& Skopeteas 2008), as is suggested by the morphological case properties of pronominal elements and the fact that preverbal agents in direct voice and postverbal subjects in inverse voice backwardscontrol the subjects of matrix control-predicates. Inverse and direct voices are associated with different word orders, however. In the SOV word order, the verb occurs in the direct voice form. In the OVS word order, the verb is marked for inverse voice and the subject constituent is accompanied by an obviative marker. Binding properties show that subject constituents may bind into objects in the SOV order, but not vice versa. The OVS order creates new binding possibilities: the subject may bind into the antecedent object.

$\begin{array}{lllllll}\text { (8) (a) bapinga } & \text { klara } & \text { klara } & \mathrm{ba}_{\mathrm{i}} & \text { opinga } & \text { e } & \text { woydë. } \\ \text { teacher } & \text { stand } & \text { stand } & 3 . \mathrm{SG} & \text { pupil } & \text { that like }\end{array}$

'Every teacher ${ }_{i}$ likes his $_{i}$ pupil.'

(b) $* \mathrm{ba}_{\mathrm{i}}$ bapinga opinga klara klara e woydë.

3.SG teacher pupil stand stand that like

(intended) ' $\mathrm{His}_{\mathrm{i}}$ teacher likes every pupil ${ }_{\mathrm{i}}$ '.

(c) $b_{i}$ opinga e woydë bapinga klara klara dë.

3.SG pupil that like teacher stand stand OBV

'Every teacher likes his $_{\mathrm{i}}$ pupil.'

The Teribe data set is presented in Table 4 (see further discussion in Quesada and Skopeteas 2008). As in the previous languages, the condition 'ag/giv' only triggers sentences in canonical order (9a), while the condition 'pat/giv' licenses inverse clauses in which the object constituent precedes the subject. The difference of the means is significant (paired samples $t$-test: $t_{3}=60.77, p<.05$ ).

(9) (a) [sc-1] \{There is a man standing.

[sc-2] domer walë poskak.

man woman push

'The man pushes a woman.' (ag/giv) 

(b) $[\mathrm{sc}-1] \quad$ \{There is a man standing.
[sc-2] domer poska-ya walë dë
man push-IPFV.INV woman OBV
'A woman pushes the man.' (pat/giv)

\begin{tabular}{|c|c|c|c|c|}
\hline & \multicolumn{2}{|c|}{ ag/giv } & \multicolumn{2}{|c|}{$\mathrm{ag} /$ new } \\
\hline & $\mathrm{n}$ & $\%$ & $\mathrm{n}$ & $\%$ \\
\hline total & 64 & & 64 & \\
\hline other & 11 & & 13 & \\
\hline $\mathrm{ag}=\mathrm{sbj} /$ first & 53 & 100 & 15 & 29.4 \\
\hline $\mathrm{ag}=\mathrm{sbj} / \mathrm{non}-\mathrm{first}$ & - & - & 36 & 70.5 \\
\hline $\mathrm{ag}=$ non-sbj/non-first & - & - & - & - \\
\hline $\mathrm{ag}=$ non-sbj/first & - & - & - & . \\
\hline
\end{tabular}

Prinmi (Yunnan, China; Tibeto-Burman) is a V-final language (see Ding 1998). There are no voice operations which could affect the alignment of $\theta$-roles to syntactic functions. The canonical order of the arguments is agent $\succ$ beneficiary $\succ$ theme, but this order is not rigid. Crucially, two suffixes occur in this language that relate to different concepts of topicalization ${ }^{14}$ : the suffix - $b b o$ ('external topic' after Ding 1998) occurs at the right edge of sentence initial constituents only. Material in this position has the properties of left dislocation: it must not have a syntactic relation to an element in the clause and it can be resumed in the main clause by a co-indexed pronoun. The available evidence does not allow for conclusions as to whether movement or in situ generation is involved (which is a general problem in East Asian languages, see Xu 2006), but it shows clearly that the sentence initial position which is optionally delimited by this suffix is not an A-position. The suffix -ggi ('internal topic'), on the other hand, occurs at the right edge of constituents in all possible positions of a sentence, optionally marking constituents which are part of the common ground. In sum, we assume that Prinmi OSV sentences come in two versions: (a) the object scrambles over the subject landing in a clause internal position, (b) the object occupies a sentence initial extra-clausal position. We assume that (b) is the case when the initial object is accompanied by the external topic marker - $b b o$.

\footnotetext{
${ }^{13}$ The Teribe data was collected by Diego Quesada and Stavros Skopeteas (Térraba reservation, Costa Rica, April 2007). 4 native speakers of Teribe participated and provided 16 data points per condition (in four different field sessions).

${ }^{14}$ Our account is based on Ding (1998) and on our interpretation of the experimental dataset of project D2.
} 
In the condition 'ag/giv \& pt/new', all valid responses exhibit SOV order, as exemplified in (10a). The given agent is always marked with the 'internal topic' marker. No instance of the external topic marker -bbo appears in our data set. In the condition 'ag/new \& pt/giv', we obtained either canonical clauses or OSV clauses as exemplified in (10b). In both cases, only the marker -ggi occurs in the data. The proportion of 'ag/non-first' clauses is significantly higher in the condition 'pat/giv' (paired samples $t$ test, $\left.t_{4}=3.98, p<.05\right)$.

(a) $[\mathrm{sc}-1] \quad\{$ A woman stood there. $\}$

[sc-2] Deanón'a hmezhá=ggi zzîn-dìn xxié=rao.

just.now=REL woman=TOP sit-INS lift=N.INV

'The woman just mentioned was lifting chair.' (ag/giv)

(b) $[\mathrm{sc}-1] \quad\{$ A flag is here. $\}$

[sc-2] Diebbòn=ggi dê peatèmi=ggon kéarao.

flag_CLF=TOP this guy=TOP.AGT push=N.INV

'This guy is pushing the flag.' (pat/giv)

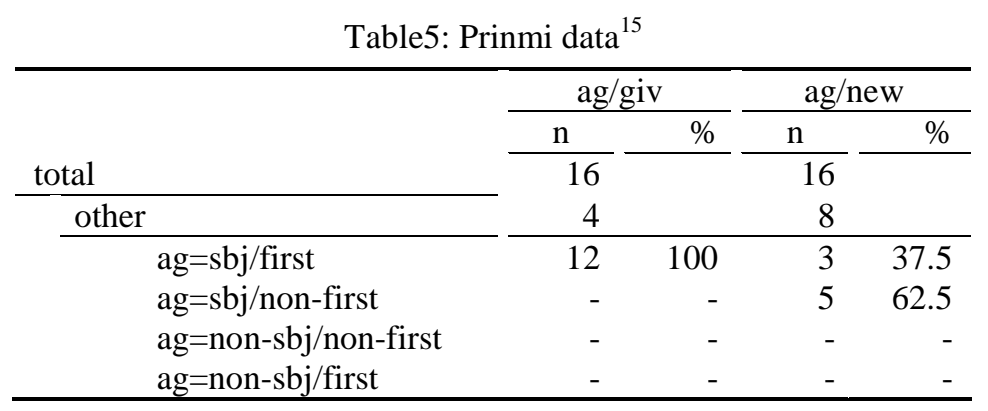

If our interpretation of $-g g i$ is correct, Prinmi is a further instance of a language that expresses givenness by means of A-movement.

Hungarian constitutes a problem for the view that givenness-related changes in word order come about by A-movement only. The canonical constituent order in Hungarian is VSO. Preverbal arguments occupy designated A'-positions for topic and focus (see Kiss 1998: 256). The grammar allows passive formation, but passives seem excluded in the context we examined for stylistic reasons (they belong to the formal register and occur mostly in written styles). All valid descriptions in the condition 'ag/giv' involve orders in which the subject precedes the object, as in (11a). The condition 'pat/giv' triggers patient fronting in a subset of the descriptions as exemplified in (11b) (see proportions in Table 6).

\footnotetext{
${ }^{15}$ The Prinmi data was collected (in Yunnan, China, January 2005) and transcribed by Shizhi Ding.
} 
The difference in the proportion of fronted objects in this condition is statistically significant (paired samples $t$-test: $\left.t_{6}=5.05, p<.05\right)$.
(a) $[\mathrm{sc}-1] \quad\{$ A man is walking. $\}$
[sc-2] A férfi rángat egy nőt.
DEF man pull:3.SG.PRS INDEF woman-ACC
'The man is pulling a woman.' (ag/giv)
(b) $[\mathrm{sc}-1] \quad\{$ There is a barrel on the bottom of the picture. $\}$

$\begin{array}{llllll}\text { [sc-2] A } & \text { hordót } & \text { most } & \text { felemeli egy } & \text { nő. } \\ \text { DEF barrel-ACC } & \text { now } & \text { up-lift-3.SG } & \text { INDEF } & \text { woman } \\ \text { 'A woman is lifting up the barrel.' (pat/giv) } & \end{array}$

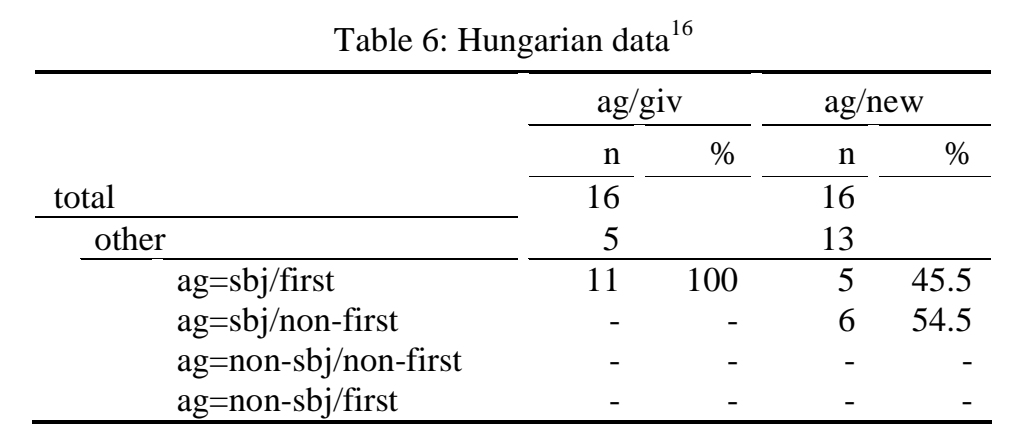

Given non-subjects are therefore able to appear in an $A^{\prime}$-position. However, Kiss (2003) argues that this $\mathrm{A}^{\prime}$-position is not filled by operator movement. If she is correct, there is no reason why purely given XPs should not be able to appear in an $\mathrm{A}^{\prime}$-position in Hungarian.

\section{The passivization strategy}

\subsection{German}

32 native speakers of German participated in the experiment, all students of the University of Potsdam. ${ }^{17}$ The following types of response were elicited: descriptions with an active verb (see $12 \mathrm{a} / \mathrm{c}$ ) and descriptions with a passive verb (see 12b); in both cases, the descriptions instantiate the canonical word order. Active descriptions (see 12a) were elicited in both conditions from condition, while passive sentences (see 12b) were only elicited in the condition 'pat/giv'. There was a single

\footnotetext{
${ }^{16}$ The data was collected (in Piliscsaba, Hungary, 2006-2007) and transcribed by Krisztián Tronka.

${ }^{17}$ German experimental sessions were conducted and transcribed by Katharina Moczko and Andreas Pankau (University of Potsdam, January-March 2006).
} 
description with non-canonical word order in the condition 'pat/giv' (see 12c). It involves a weak object pronoun which is obligatorily placed at the highest position of the midfield in German for syntactic rather than information structural reasons.

(a) [sc-1] 'A boy stands on a carpet...'

[sc-2] ...dieser Junge schubst eine grüne Sektflasche um...

'...this boy pushes a green champagne-bottle.'

(decoded as 'ag=sbj/first'; condition 'ag/giv')

(b) [sc-1] 'A girl is running...'

[sc-2] ...das Mädchen wird von einem Mann gegriffen und umgeschmissen...

'...the girl is grasped and knocked down by a man.'

(decoded as 'ag=non-sbj/non-first'; condition 'pat/giv')

(c) [sc-1] 'A boy stands annoyed on a staircase...'

[sc-2] ...und plötzlich schubst ihn ein Mädchen von hinten. (pat/giv)

'...and suddenly a girl pushes him from the backside.'

(decoded as 'ag=sbj/non-first'; condition 'pat/giv')

The effect of givenness on word order manifests itself in the significant difference in the percentage of passive clauses between the condition 'ag/giv' (0\%) and the condition 'pat/giv' (21.3\%) (paired samples $t$-test: $\left.t_{23}=3.61, p<.05\right)($ see proportions in Table 7).

Table 7: German data

\begin{tabular}{|c|c|c|c|c|}
\hline & \multicolumn{4}{|c|}{ German } \\
\hline & \multicolumn{2}{|c|}{ ag/giv } & \multicolumn{2}{|c|}{ pat/giv } \\
\hline & $n$ & $\%$ & $n$ & $\%$ \\
\hline total & 64 & & 64 & \\
\hline other & 19 & & 17 & \\
\hline $\mathrm{ag}=\mathrm{sbj} /$ first & 45 & 100 & 36 & 76.6 \\
\hline $\mathrm{ag}=\mathrm{sbj} /$ non-first & - & - & 1 & 2.1 \\
\hline $\mathrm{ag}=$ non $-\mathrm{sbj} /$ non-first & - & - & 10 & 21.3 \\
\hline $\mathrm{ag}=$ non-sbj/first & - & - & - & - \\
\hline
\end{tabular}

In the condition 'ag/giv \& pat/new', 14 out of the 45 agent expressions (23.7\%) are pronominal. In the condition 'ag/new \& pat/giv', 6 out of the 47 patient expressions in German (11.3\%) are pronominal. 3 out of 6 clauses with a pronominal patient contain a passive verb, which suggests that passivization is 
more frequent with pronominal patients (50\% passive clauses with pronominal patients vs. 7 out of 41 , i.e. $14.5 \%$ passive clauses with lexical patients), though the small numbers do not allow us to prove the statistical significance of this difference.

In contexts with a given patient and a new agent, participants of the German experiment used passivization rather than simple reordering for producing $\mathrm{G} \succ \mathrm{N}$ order. This outcome is surprising for two reasons. First, the result does not fit comparative and theoretical expectations. While previous cross-linguistic studies (Mathesius 1975, Prat Sala 1997) have shown that some languages use passives in contexts in which others use simple reordering, these studies explain this difference in terms of overall word order flexibility. Syntactically, German is, however, a free word order language allowing scrambling and movement of the object to $\mathrm{Spec}, \mathrm{CP}$, so one does not expect the preference for grammatical function change found in our data. Second, our result seems incompatible with corpus data. Weber \& Müller (2004) found more OVS (144) than SVO (88) sentences in contexts with given patients and new agents. In natural (newspaper) text, the givenness of an object seemingly licenses preposing in main clauses without passivization. Kempen and Harbusch (2005) observed an unexpected rigidity of word order in embedded clauses: they found only four instances of $\mathrm{O} \succ \mathrm{S}$ order with two lexical arguments against 1476 instances of $\mathrm{S} \succ \mathrm{O}$ order $(0.2 \%)$ in a corpus of written texts (NEGRA), and one instance of $\mathrm{O} \succ \mathrm{S}$ against 132 instances of $\mathrm{S} \succ \mathrm{O}(0.7 \%)$ in a corpus of oral texts (VERBMOBIL). In general, structures in which an object is fronted across an underlying subject but not placed into the preverbal position of a main clause are very rare: there are between 1 and 2 occurrences of such structures per 1,000 sentences.

The fact that our experiment yielded marked word order sentence in Georgian and further languages, it excludes the possibility that some overall suboptimal design property is responsible for the absence of a simple word order variation in German.

Let us first deal with the contrast between corpus studies and our experimental findings. The movement of a given object to first position observed in corpora is not necessarily triggered by the givenness of the object itself. The trigger for such displacements may be another pragmatic function compatible with givenness. Only half of the objects in OVS sentences are given and precede new 
subjects in Weber \& Müller (2004), a figure that is reminiscent of Speyer's (2007) observation that only half of all XPs in Spec,CP represent 'backward looking centers', i.e. given topics. It is certain that the appearance of XPs in first position can fulfil other functions than expressing givenness.

Givenness was directly controlled in our experiment (so that its effects should be visible in the results), but further pragmatic factors are not likely to show an effect in our production study. Natural texts differ from our experimental situation in that the fronting of given XPs may be called for because of subsequent text (enhancement of anaphoric options, the preparation or execution of topic shifts, etc.). All such potential continuing functions are not expected for the description of the second picture in the mini-texts elicited from our informants. Contrast plays no role in our experimental setting either, and marked $\mathrm{O} \succ \mathrm{S}$ order in our simple picture description design cannot be motivated by further communicative needs such as directing the hearer's (=instructor's) attention. We thus believe that our results show the pure effects of givenness that are blurred by a multitude of other factors in natural texts (e.g., animacy, weight, contrast to other referents, etc.).

Speyer's (2007) shows that what goes to first position (Spec,CP) is primarily determined by contrast, the introduction of brand-new information, and the introduction of elements standing in a POSET relation (see Prince 1997) to given material. These factors override "topicality" in the choice of the element occupying Spec,CP. Frey (2004) shows that it is not "familiarity" (strongly related to givenness) but "aboutness" that determines whether an element moves leftwards to a topic position. This is in line with our findings: the givenness of an object is not a sufficient reason for movement across the subject.

We can now turn to the first question: why is givenness not able to trigger movement in German? Half of the answer is easy. The left peripheral position $\mathrm{Spec}, \mathrm{CP}$ is an $\mathrm{A}^{\prime}$-position. Movement to $\mathrm{A}^{\prime}$-positions creates operator-variable dependencies. Categories such as contrast, focus, and topicality can be interpreted along these lines, but pure givenness is normally not amenable to a treatment as an operator-variable relation. Given material therefore cannot reach $A^{\prime}$-positions directly (though they may be attracted there if they additionally bear operator properties).

However, the left periphery of German main clauses also hosts non-operator material: the leftmost category of the narrow clause (TP) can go to Spec,CP, too (see Fanselow 2003, Müller 2004, Frey 
2005). Typically, this leftmost position of TP is occupied by subjects, sentence level and temporal adverbs, but objects can reach this position by scrambling, too. The difficult half of finding an answer to the question of why given objects cannot be fronted thus is: Why is givenness not sufficient for the application of object scrambling in German? Why is scrambling of accusative objects so rare in natural texts, and non-existent in our data?

\subsection{Further Languages}

Four further languages will be presented in this section that - though structurally different from German to different degrees - show the same data pattern in this experimental condition: American English, Québec French, Dutch, and Yucatec Maya.

All four languages have productive passivization, but they differ from German in that A-scrambling is not grammatically available. Nevertheless, non-canonical orders are possible in these languages as well (see inversion, preposing, and dislocation in Birner \& Ward 2004 for English), but they involve operator movement, and are thus not expected to be invoked by a simple asymmetry in givenness. Dutch is similar to German in terms of SOV base order and the verb-second effect. Objects may scramble over adverbs (see Neeleman \& Reinhart 1998) but not over subjects (at least not in noncontrastive contexts).

The examples in (a) illustrate canonical sentences produced in the condition 'ag/giv' and the examples in (b) illustrate expressions obtained in the condition 'pat/giv', showing that givenness asymmetries can trigger passivization.

(13) (a) [sc-1] \{A woman is standing with her hands on her hips.

[sc-2] La femme frappe un homme dans l'dos.

'The woman is hitting the man in the back.' (ag/giv)

(b) [sc-1] \{There is a young boy running. $\}$

[sc-2] Le jeune garçon est attrapé par un homme.

'The young boy is caught by a man.' (pat/giv) 
(14)

(a) $[\mathrm{sc}-1] \quad\{$ There's a man walking. $\}$

[sc-2] Now the man is attacking a woman. (ag/giv)

(b) [sc-1] \{There's a woman who's walking. $\}$

[sc-2] Now she's attacked by a man from behind. (pat/giv)

(15)

(a) $[\mathrm{sc}-1] \quad$ A man is standing on the end of the glide. $\}$

[sc-2] De man duwt een band de glijbaan op.

'The man pushes a tire up the glide.' (ag/giv)

(b) $[\mathrm{sc}-1] \quad\{$ There is a small table on a staircase. $\}$

[sc-2] Eh, de tafel wordt door een meisje van de trap geduwd.

'The table is pushed from the staircase by a girl.' (pat/giv)

The results for these three languages are summarized in Table 8 . The differences in the two conditions are in accordance with our hypothesis and are significant in all languages (French data: $t_{7}=2.39, p<$ .05 ; English data: $t_{13}=2.48, p<.05$; Dutch data: $\left.t_{6}=2.42, p<.05\right)$.

Table 8: Canadian French, American English, and Dutch data ${ }^{18}$

\begin{tabular}{|c|c|c|c|c|c|c|c|c|c|c|c|c|}
\hline & \multicolumn{4}{|c|}{ Canadian French } & \multicolumn{4}{|c|}{ American English } & \multicolumn{4}{|c|}{ Dutch } \\
\hline & \multicolumn{2}{|c|}{ ag/giv } & \multicolumn{2}{|c|}{ ag/new } & \multicolumn{2}{|c|}{ ag/giv } & \multicolumn{2}{|c|}{ ag/new } & \multicolumn{2}{|c|}{ ag/giv } & \multicolumn{2}{|c|}{ ag/new } \\
\hline & $n$ & $\%$ & $n$ & $\%$ & $n$ & $\%$ & $n$ & $\%$ & $n$ & $\%$ & $n$ & $\%$ \\
\hline total & 16 & & 16 & & 48 & & 48 & & 16 & & 16 & \\
\hline other & 1 & & 5 & & 14 & & 24 & & 5 & & 2 & \\
\hline ag=sbj/first & 15 & 100 & 8 & 72.7 & 34 & 100 & 20 & 83.7 & 11 & 100 & 10 & 71.4 \\
\hline $\mathrm{ag}=\mathrm{sbj} /$ non-first & - & - & - & - & - & - & - & - & - & - & - & - \\
\hline $\mathrm{ag}=$ non-sbj/non-first & - & - & 3 & 27.3 & - & - & 4 & 16.3 & - & - & 4 & 28.6 \\
\hline $\mathrm{ag}=$ non-sbj/first & - & - & - & - & - & - & - & - & - & - & - & - \\
\hline
\end{tabular}

In Yucatec Maya (Yucatán/Quitana Roo, Mexico; Maya), objects precede subjects in canonical word order. Like most Mayan languages, Yucatec Maya is V-initial, the canonical position of postverbal arguments being VOS (Durbin \& Ojeda 1978). However, this order occurs only very rarely in corpora and is difficult to process (see Skopeteas \& Verhoeven 2005, Gutiérrez Bravo and Monforte y Madera 2007). In our experiment, we encountered a single VOS clause, given in (17c), but since this is a single instance of this order, we cannot draw conclusions about its interaction with the examined discourse conditions. As already observed in corpora (see Skopeteas \& Verhoeven 2005, Gutiérrez

\footnotetext{
${ }^{18}$ The data from Canadian French was collected and transcribed by Alain Thériauld (Québec, December 2005-February 2006), and the data from Dutch by Hanneke Van Hoof (Rijswijk, Netherlands, 2006). The data from American English was collected and transcribed by Elizabeth Medvedovsky (Chicago, December 2005) and involves a larger sample (24 native speakers).
} 
Bravo and Monforte y Madera 2007), the order that most frequently occurs in corpora is SVO, involving a left dislocated subject constituent (constituents in this position may be resumed in situ by a co-referent pronoun or noun and cannot occur in some subtypes of subordinate clauses). Hence, in the condition 'ag/giv' we obtained 20 descriptions with SVO order as illustrated in (16a). Given that the basic VOS order hardly has a chance of being realized, two structural configurations allow for patients preceding agent constituents. The first structural configuration which results in a fronted patient is left dislocation of the object involving $\mathrm{A}^{\prime}$-movement of this constituent. Active clauses with left dislocated patients do not occur in our data set at all. The second configuration is passive voice, exemplified in (16b).
(a) $[\mathrm{sc}-1]$
\{There is a man standing. \}
[sc-2]
te'el-a' le máak-o' táan u ch'ik
le sáarten-o'.
this-D.1 DEFman-D.2 PROG A.3 take(B.3.SG) DEF pan-D.2
'In this (scene), the man is taking the pan.' (ag/giv)

(b) $[\mathrm{sc}-1] \quad\{$ The pan is on the little table. $\}$

[sc-2] le sáarten-o' tuún liík's-a'l yo'l le meèsa-o'.

DEF pan-D. 2 PROG:A.3 lift-PASS.INCMPL on DEF table-D.2

'The pan is being lifted from the table.' (pat/giv)

(c) $[\mathrm{sc}-1] \quad\{$ Here is a chair ... $\}$

[sc-2] lela' muka'h u koh le k'áanche'-o' máak-o'

it:D1 IMM.FUT A.3 push(SUBJ)(B.3.SG) DEFchair-D.2 person-D2

be'òraáh le chàan boòláah yéetel hun-p'éel máartillóoh.

now DEF little ball with one-CL.INAN hammer

'[on] this [picture], a man is going to push the chair.' (pat/giv)

Table 9 shows that Yucatec Maya chooses the passivization option (13 clauses, i.e. 56.5\%). Hence, Yucatec Maya displays the same pattern as German or English. The proportion of passive clauses is significantly higher in the condition 'pat/giv' $\left(t_{7}=5.11, p<.05\right.$, measured on items due to the low number of subjects, $n=2)$. 
Table 9: Yucatec Maya data ${ }^{19}$

\begin{tabular}{|c|c|c|c|c|}
\hline & \multicolumn{2}{|c|}{ ag/giv } & \multicolumn{2}{|c|}{ ag/new } \\
\hline & $\mathrm{n}$ & $\%$ & $\mathrm{n}$ & $\%$ \\
\hline total & 32 & & 32 & \\
\hline other & 11 & & 8 & \\
\hline $\mathrm{ag}=\mathrm{sbj} /$ first & 20 & 95.2 & 10 & 41.6 \\
\hline $\mathrm{ag}=\mathrm{sbj} /$ non-first & - & - & 1 & 4.2 \\
\hline $\mathrm{ag}=$ non-sbj/non-first & 1 & 4.8 & 13 & 54.2 \\
\hline $\mathrm{ag}=$ non$-\mathrm{sbj} /$ first & - & - & - & - \\
\hline
\end{tabular}

\section{Canonical word order strategy}

The previous sections presented two strategies for placing given patients in front to new agents. In a third language type, patients are not fronted at all when they outrank agents in givenness. This data pattern is attested in Greek. Greek is a VSO language with preverbal operator positions. There is morphological medio-passive formation, which is strongly defective and lexically varies in the availability of passive or middle voice. Crucially, for most verbs occurring in our experiment, the medio-passive form has reflexive and reciprocal functions blocking its use in passive voice.

The alternative to passive formation in Greek would be an OVS order which is derived by movement of the object to an operator position. Preverbal object topics trigger a co-referent proclitic pronoun resulting in a construction that is known as clitic left dislocation, which under standard assumptions involves $A^{\prime}$-movement (see Alexiadou \& Anagnostopoulou 2000). It has been already noted in the literature that clitic left dislocation in Greek is functionally equivalent to passivization in English (see Warburton 1975). However, accounts on the discourse function of clitic left dislocation do not assume that this construction is triggered by givenness asymmetries but refer to discourse concepts such as contrastive topicalization (Iatridou 1995) or linkhood of the object constituent (see Alexopoulou and Kolliakou 2001). Hence, we do not expect to obtain instances of clitic left dislocation in a context that

\footnotetext{
${ }^{19}$ The data presented in this table was produced by 2 speakers that gave 16 descriptions per condition each (in 8 field sessions). The data was collected and transcribed by Stavros Skopeteas and Elisabeth Verhoeven (August 2006). A previous data set based on a pilot version of the same experiment was collected with 12 speakers in December 2004 and showed the same data pattern. All informants are native speakers and inhabitants of Quintana Roo, Mexico.
} 
involves a simple givenness asymmetry of the arguments, and this prediction is borne out (see Table 10).

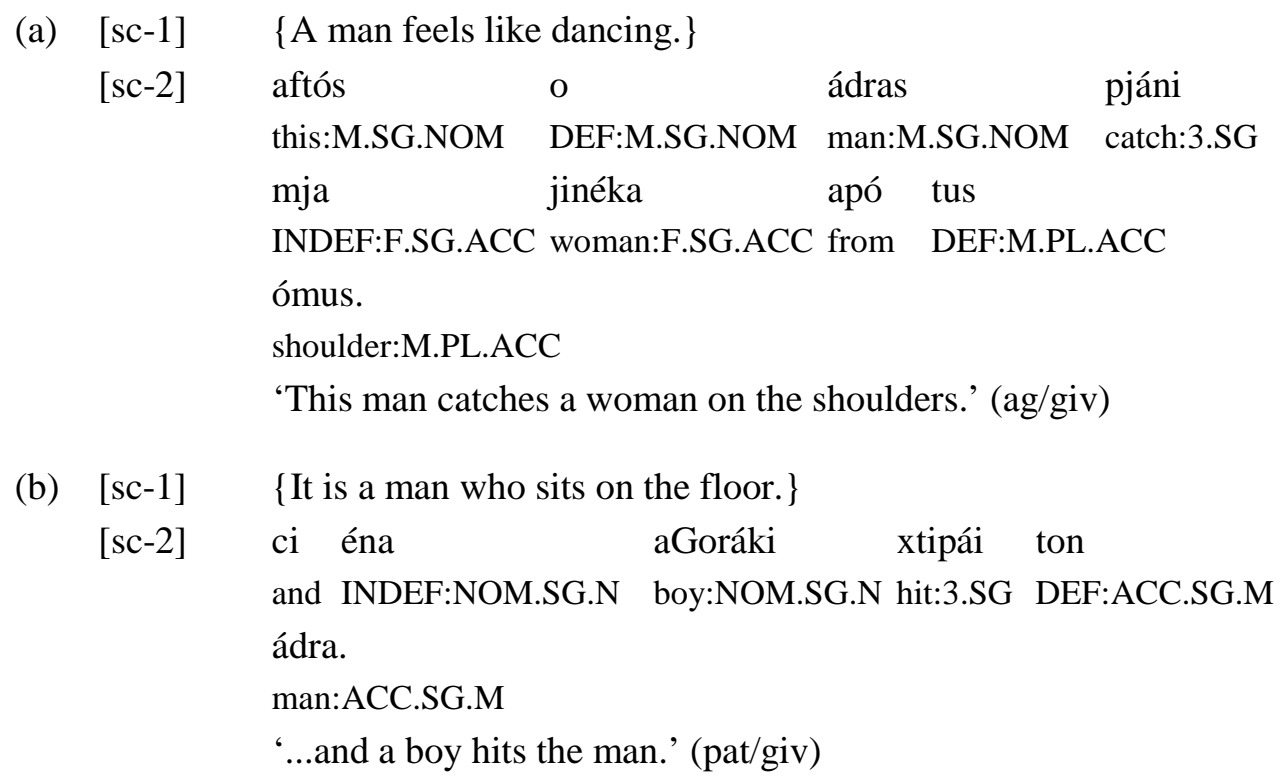

Table 10: Greek data ${ }^{20}$

\begin{tabular}{|c|c|c|c|c|}
\hline & \multicolumn{2}{|c|}{ ag/giv } & \multicolumn{2}{|c|}{ ag/new } \\
\hline & $\mathrm{n}$ & $\%$ & $\mathrm{n}$ & $\%$ \\
\hline total & 32 & & 32 & \\
\hline other & 15 & & 12 & \\
\hline$a g=s b j /$ first & 17 & 100 & 20 & 100 \\
\hline $\mathrm{ag}=\mathrm{sbj} /$ non-first & - & - & - & - \\
\hline $\mathrm{ag}=$ non $-\mathrm{sbj} /$ non-first & - & - & - & - \\
\hline $\mathrm{ag}=$ non $-\mathrm{sbj} / \mathrm{first}$ & - & - & - & - \\
\hline
\end{tabular}

\section{Discussion}

Our cross-linguistic results show that the condition 'ag/giv' induces canonical sentences across languages, while the condition 'pat/giv' licenses deviations from the canonical pattern (see summary in the last column of Table 11). The second column in Table 11 shows that a subset of the sample languages have (in-)definite markers, including Prinmi, which has a suffix marking the discourse status of the NP. The next column shows that a subset of the languages displays an overt case opposition for the distinction between agent and patient constituents. Basic word order is given in the next column. All grammars have some structural configuration that involves an operator position and may serve as the landing site of $A^{\prime}-$ movement. The grammars differ with respect to the availability of

\footnotetext{
${ }^{20}$ The data was collected and transcribed by Thanasis Georgakopoulos and Yannis Kostopoulos in collaboration with George Markopoulos (Athens, January-March 2006).
} 
operations that allow movement to an argument position. Some grammars have scrambling, and some grammars allow passivization. Note that for some languages these structural possibilities are subject to constraints of a stylistic or structural nature, so that they do not constitute real options in the production process we examined. For example, passive voice is stylistically excluded in Georgian and Hungarian and does not occur due to defectivity and semantic blocking in our Greek sample.

Table 11: Summary

\begin{tabular}{|c|c|c|c|c|c|c|c|}
\hline & \multirow[b]{2}{*}{ def. } & \multirow[b]{2}{*}{ case } & \multirow[b]{2}{*}{ w.o. } & \multirow{2}{*}{$\begin{array}{l}\text { operator } \\
\text { position }\end{array}$} & \multicolumn{2}{|c|}{ argument position } & \multirow{2}{*}{$\begin{array}{l}\text { difference in } \\
\text { 'pat/giv' }\end{array}$} \\
\hline & & & & & reordering & passive & \\
\hline Georgian & - & $\checkmark$ & $\overline{\mathrm{SOV}}$ & $\checkmark$ & $\checkmark$ & restricted & reordering \\
\hline Konkani & $\checkmark$ & $\checkmark$ & SOV & $\checkmark$ & $\checkmark$ & - & reordering \\
\hline Prinmi & $\checkmark$ & $\checkmark$ & SOV & $\checkmark$ & $\checkmark$ & - & reordering \\
\hline Teribe & - & - & SOV & $\checkmark$ & $\checkmark$ & - & reordering \\
\hline Am. English & $\checkmark$ & - & SVO & $\checkmark$ & - & $\checkmark$ & passivization \\
\hline Can. French & $\checkmark$ & - & SVO & $\checkmark$ & - & $\checkmark$ & passivization \\
\hline Dutch & $\checkmark$ & - & SOV & $\checkmark$ & $(\checkmark)$ & $\checkmark$ & passivization \\
\hline Yucatec Maya & $\checkmark$ & - & VOS & $\checkmark$ & - & $\checkmark$ & passivization \\
\hline German & $\checkmark$ & $\checkmark$ & SOV & $\checkmark$ & $\checkmark$ & $\checkmark$ & passivization \\
\hline Czech & - & $\checkmark$ & SVO & $\checkmark$ & $\checkmark$ & $\checkmark$ & reordering \\
\hline Greek & $\checkmark$ & $\checkmark$ & VSO & $\checkmark$ & - & restricted & (no difference) \\
\hline Hungarian & $\checkmark$ & $\checkmark$ & SVO & $\checkmark$ & $\checkmark$ & restricted & reordering \\
\hline
\end{tabular}

It has to be noticed that the typological classification in Table 11 relates to the expression of givenness asymmetries and not to word order freedom in general, i.e., the same languages may show different data patterns in other discourse conditions.

Definite and indefinite articles contrast for the distinction of given and new specific referents in the examined context. Hence, the availability of definiteness in a language may be assumed to have a compensatory effect on the use of syntactic means for the encoding of givenness. However, our data shows that this is not the case. The use of marked word order and the choice between scrambling and passivization are independent of the presence/absence of definiteness markers.

General word order freedom is well-correlated with the existence of morphological case distinctions and with the VO/OV distinction. As mentioned above, the general tendency in our small language sample is that OV languages can apply their scrambling operation to given arguments. Hindi and Turkish (Temürcü 2001) support this tendency. Dutch and German are the only exceptions in this 
context, with German being a scrambling language but not applying the process for givennessmarking. The idea suggests itself that it is the verb second property of these languages that comes in the way of fully exploiting the potential of OV languages, but our sample is too small to really warrant such a conclusion, and it is unclear how such a negative correlation between verb second movement and the use of scrambling for givenness marking could be derived from syntactic models.

We argued that givenness-induced word order variation depends on the availability of argument positions in syntax. Our data suggests the following generalizations ${ }^{21}$ :

(18) a. Givenness asymmetries do not induce $A^{\prime}$-movement.

b. Givenness asymmetries may induce A-movement (either of the reordering or of the passive type).

These generalizations are supported by rich evidence from our data set. All languages in our sample have the structural option of moving an XP to an operator position, but with one possible exception: speakers never choose this option for expressing givenness. Strong support for the view that givenness is incompatible with operator/A'-movement is found in the Greek data. Passivization in Greek does not apply in the examined context and clitic left dislocation would be the only way to achieve a linearization which satisfies the pragmatic preference for given information to precede new. This construction involves $\mathrm{A}^{\prime}$-movement, however, which is not induced by givenness asymmetries, as shown by our experimental results and in line with the previous literature on the information structural properties of clitic left dislocation.

However, generalization (19) fails to explain the Hungarian data. Though object fronting involves $\mathrm{A}^{\prime}$-movement in this language, this construction is effectively induced by givenness asymmetries. This finding suggests that $\mathrm{A}^{\prime}$-movement in Hungarian has different syntactic or information structural properties. If Kiss (2003) is correct, the relevant exceptional property of Hungarian would lie in the fact that $\mathrm{A}^{\prime}$-movement to topic positions is not operator movement in Hungarian. The discussion in Baker (2000) shows that Hungarian is not exceptional in failing to align certain A'-positions with operator status.

\footnotetext{
${ }^{21}$ See very similar results and generalizations in Neeleman and van de Koot (2007).
} 
Turning now to the types of A-movement that occur across languages, we observe a preference for Ascrambling in our language sample. As remarked above, German is an exception to this in that it does not apply its scrambling operation for the expression of givenness contrasts. In a sense, Czech is an exception, too, because it is the only language in which we find variation between scrambling and passive in the picture descriptions. All other languages adopt a single strategy for expressing givenness only.

A large part of the data set is explained through the available options in the grammar. Speakers of Konkani, Prinmi, and Teribe do not have a passivization option and they (optionally) select reordering in order to linearize the propositional content according to the pragmatic preferences. Speakers of American English, Canadian French, Dutch, and Yucatec Maya do not have the scrambling option; hence, they select passivization. German and Czech illustrate the critical case in which both options are available, but their reactions are not uniform: German speakers opt for passivization, while Czech speakers prefer reordering in the same context.

We found that given material is only optionally fronted in the languages of our sample. The optionality of givenness fronting in our data is compatible with those grammatical models that view scrambling as a (syntactically) 'non-triggered' operation (Haider \& Rosengren 2003) or assume that scrambled structures are base-generated (Fanselow 2001). Likewise, the choice of passive morphology is syntactically untriggered in many grammatical models (though it may trigger a number of syntactic consequences such as A-movement). In other words, our results corroborate the view that scrambling and passivization are not only optional from a purely syntactic point of view but also in terms of the expression of information structure. Our findings therefore disfavor grammatical models in which there is no untriggered movement and models such as classical OT in which conflicts such as those between ordering principles are (nearly) always resolved in a unique way. Our findings favor syntactic models in which a 'gradient' conflict resolution is not exceptional or models in which the actual choice between syntactic constructions is not part of the theory of syntax.

We have not considered the impact of prosody in the present paper. Given phrases are obligatorily deaccented in German (see Féry and Herbst 2004, Féry 2006, Féry and Ishihara, this volume). Where deaccentuation is the formal counterpart of givenness, the word order changes induced by givenness 
can be conceived of as being caused in an indirect way. The object position is typically the most prominent one prosodically, and the fronting of given objects has the effect of 'optimizing' prosodic structure in the sense that deaccented material leaves that prominent position. We believe that the optionality of givenness fronting can be understood in terms of this interaction between syntax and prosody.

\section{Abbreviations}

\begin{tabular}{|c|c|c|c|}
\hline 1 & $1^{\text {st }}$ person & LOC & locative \\
\hline 2 & $2^{\text {nd }}$ person & M & masculine \\
\hline 3 & $3^{\text {rd }}$ person & N.INV & non-involvemental (evidential) \\
\hline A & class A (person affix) & NOM & nominative \\
\hline ACC & accusative & NV & neutral version \\
\hline $\mathrm{ADV}$ & adverbializer & OBL & oblique \\
\hline AGT & agentive & OBV & obviative \\
\hline ANIM & animate & $\mathrm{OV}$ & object version \\
\hline B & class B (person affix) & PASS & passive voice \\
\hline CLF & classifier & PL & plural \\
\hline $\mathrm{D}$ & definite & POS & possessive \\
\hline DAT & dative & PROG & progressive \\
\hline DIM & diminutive & PRS & present \\
\hline $\mathrm{F}$ & feminine & PV & preverb \\
\hline GEN & genitive & REL & relationalizer \\
\hline INCMPL & incompletive & RFL & reflexive \\
\hline INDEF & indefinite & $\mathrm{S}$ & subject (person affix) \\
\hline INS & instrumental & SG & singular \\
\hline INV & inverse voice & THM & thematic suffix \\
\hline IO & indirect object (person affix) & TOP & topic \\
\hline IPFV & imperfective & & \\
\hline
\end{tabular}

\section{References}

Alexiadou, Artemis and Elena Anagnostopoulou 2000, Greek syntax: A principles and parameters perspective. Journal of Modern Greek Linguistics 1, 171-222.

Alexopoulou, Theodora and Dimitra Kolliakou 2002, On linkhood, topicalization, and clitic left dislocation. Journal of Linguistics 38.2, 193-245. 
Amiridze, Nino 2006, Reflexivization strategies in Georgian. Ph. D. dissertation, University of Utrecht. Utrecht: LOT.

Anderson, Stephen R. 1984, On representations in morphology: case, agreement, and inversion in Georgian. Natural Language and Linguistic Theory 2, 157-218.

Aronson, H.I. 1994, Paradigmatic and syntagmatic subject in Georgian. In: Aronson, H. I. (ed.), NonSlavic Languages of the USSR, Papers from the Fourth Conference. Columbus, OH: Slavica Publishers, 13-33.

Baker, Mark 2000, The Natures of Nonconfigurationality. In: Mark Baltin \& Chris Collins (eds.), Handbook of contemporary syntactic theories. London: Blackwell: 407-438.

Benz, Lena 2008, Sprachvergleich: Deutsch-Russisch, Wortstellung vs. Passivierung, Effekte der Gegebenheitsmanipulation von Satzargumenten transitiver und intransitiver Verben. Ms., Universität Potsdam.

Birner, Betty and Gregory Ward 2004, Information Structure and Non-canonical Syntax. In: Horn, Laurence R. and Gregory Ward (eds.), The Handbook of Pragmatics. Oxford: Blackwell, 153-174. Boeder, Winfred 1989, Verbal person marking, noun phrase and word order in Georgian. In: Marácz, László and Pieter Muysken (eds.), Configurationality: The typology of asymmetries. Dodrecht: Foris, 159-184.

Chomsky, Noam 1981, Lectures on government and binding. Dordrecht: Foris.

Clark, Herbert and Eve Clark, 1977, Psychology and language: An introduction to psycholinguistics. Psychology and language: An introduction to psycholinguistics. New York: Harcourt Brace Jovanovich.

Clark, Herbert and Susan Haviland 1977, Comprehension and the given-new contrast. In: Freedle, Roy O. (ed.) Discourse production and comprehension, 1-40. Hillsdale, NJ: Lawrence Erlbaum Associates.

Collins, Peter 1995, The indirect object construction in English: an informational approach. Linguistics 33: 35-49.

Déprez, Viviane 1989, On the typology of syntactic positions and the nature of chains. Ph.D. dissertation, Cambridge/Mass: MIT. 
Ding, Sizhi 1998, Fundamentals of Prinmi (Pumi): A Tibeto-Burman Language of Northwestern Yunnan, China. Ph. D. dissertation, Australian National University.

Durbin, M. \& Ojeda, F. 1978, Basic word-order in Yucatec Maya. In: England, N.C. (ed.), Papers in Mayan Linguistics, vol. 2. Columbia: University of Missouri, Department of Anthropology, 69-77.

Du Bois, John W. 2003, Argument structure: Grammar in use. In Du Bois, John, Lorraine E. Kumpf, William J. Ashby (eds.), Preferred argument structure: Grammar as architecture for function. Amsterdam/Philadelphia: Benjamins, 11-60.

Fanselow, Gisbert 2001, Features, 9-Roles, and Free Constituent Order. Linguistic Inquiry 32, 405437.

Fanselow, Gisbert 2003, Münchhausen-Style Head Movement and the Analysis of Verb Second. In: Anoop Mahajan (ed.), Head Movement and Syntactic Theory, volume 10 of UCLA/Potsdam Working Papers in Linguistics.

Féry, Caroline 2006, The prosody of topicalization. In Schwabe, Kerstin and Winkler, Susanne (eds.), On information structure: meaning and form. Amsterdam, Philadelphia: Benjamins, 69-86.

Féry, Caroline and Herbst, Laura 2004, German sentence accent revisited. ISIS 1, 43-75.

Frey, Werner 2004, A medial topic position for German. Linguistische Berichte 198, 153-190.

Frey, Werner 2005, Zur Syntax der linken Peripherie im Deutschen. To appear in: F. d'Avis (ed.), Deutsche Syntax: Empirie und Theorie, Göteborger Germanistische Forschungen.

Gutiérrez Bravo, Rodrigo and Monforte y Madera, Jorge 2007, La alternancia sujeto inicial/verbo inicial y la teoría de la optimidad. Ms.

Haider, Hubert \& Rosengren, Inger 2003, Scrambling: Nontriggered chain formation in OV languages. Journal of Germanic Linguistics 15.3, 203-267.

Harris, Alice C. 1981, Georgian Syntax: A Study in Relational Grammar. Cambridge etc.: Cambridge University Press.

Herring, Susan C. and Polillo, John C. 1995, Focus position in SOV languages. In: Downing, Pamela and Noonan, Michael (eds.), Word order in discourse. Amsterdam/Philadelphia: Benjamins, 163198. 
Hewitt, B.G. 1995, Georgian: A Structural Reference Grammar. Amsterdam, Philadelphia: Benjamins.

Iatridou, Sabine 1995, Clitics and island effects. Penn Working Papers in Linguistics 2, 11-31.

Ivanishvili, Marine and Soselia, Ether (1999), A morphological structure and semantics of the Georgian so-called passive forms. Proceedings of the Fourth International Tbilisi Symposium on Language, Logic, and Computation, Batumi 1999.

Joppen-Hellwig, Sandra 2001, Verbklassen und Argumentlinking: Nicht-kanonische Argumente, Expletiva und vierstellige Kausativa in Ergativ-versus Akkusativsprachen. Tübingen: Niemeyer.

Kempen, Gerard, and Karin Harbusch 2005, The relationship between grammaticality ratings and corpus frequencies: A case study into word order variability in the midfield of German clauses. In: Kepser, Stephan and Marga Reis (eds.), Linguistic Evidence - Empirical, Theoretical, and Computational Perspectives. Berlin: Mouton De Gruyter. 327-347

Kidwai, A. 2000, XP-adjunction in universal grammar: scrambling and binding in Hindi-Urdu. New York: Oxford University Press.

Kiss, Katalin É. 1998, Identificational vs. information focus. Language 74 (2), 245-273.

Kiss, Katalin É. 2003, Argument scrambling, operator movement, and topic movement in Hungarian. In: Simin Karimi (ed.), Word Order and Scrambling. London: Blackwell, 22-43.

Krifka, Manfred 2007, Basic notions of information structure. In: Féry, Caroline, Gisbert Fanselow, and Manfred Krifka (eds.), The notions of information structure. ISIS 6, 13-55.

Kučerová, Ivona 2007, The syntax of givenness. Ph.D. dissertation, MIT.

Mahajan, Anoop K. 1990, The A/A-bar distinction and Movement Theory, Ph.D. dissertation, Massachusetts Institute of Technology, Cambridge, Massachusetts.

Mathesius, Vilém 1975, A functional analysis of present day English on a general linguistic basis [ed. by J. Vachek]. The Hague, Paris: Mouton.

McGinnis, Martha 2004, Lethal ambiguity. Linguistic Inquiry 35.1, 47-95.

Morimoto, Yukiko 2000, Discourse configurationality in Bantu morphosyntax. Ph.D. dissertation, Stanford University. 
Müller, Gereon 2004, Verb-second as vP-first. Journal of Comparative Germanic Linguistics 7.3, 179234.

Müller, Gereon and Wolfgang Sternefeld 1994, Scrambling as A-bar movement. In: Corver, Norbert and van Riemsdijk, Henk (eds.), Studies on Scrambling. Berlin: Mouton De Gruyter, 331-385.

Neeleman, Ad and Hans van de Koot 2007, The Nature of Discourse Templates. Ms., UCL.

Neeleman, Ad and Tanya Reinhart 1998, Scrambling and the PF Interface. In: Miriam Butt and W. Geuder (eds.), The Projection of Arguments. CSLI Publications, Stanford. 309-353.

Oehrle, Richard T. 1976, The Grammatical Status of the English Dative Alternation. PhD dissertation, MIT.

Prat Sala, Mercè 1997, The production of different word orders: A psycholinguistic and developmental approach. Ph.D. dissertation, University of Edinburgh.

Prince, Ellen F. 1997, On the functions of left-dislocation in English discourse. In Kamio, Akio (ed.), Directions in functional linguistics. Amsterdam and Philadelphia: Benjamins, 117-143.

Quesada, Juan Diego 2000, Teribe. München, etc.: Lincom Europa.

Quesada, Juan Diego and Stavros Skopeteas 2008, The discourse functions of inverse voice: an experimental study in Teribe (Chibchan). Ms., University of Postdam and Universidad Nacional de Costa Rica.

Siewierska, Anna. 1993. On the interplay of factors in the determination of word order. In: Joachim Jacobs et al. (eds), Syntax: An International Handbook of Contemporary Research . Berlin: Walter de Gruyter, 826-846.

Skopeteas, Stavros and Gisbert Fanselow 2008, Focus in Georgian and the expression of contrast. Ms. University of Potsdam (submitted to Lingua).

Skopeteas, Stavros, Caroline Féry, and Rusudan Asatiani 2009, Word order and intonation in Georgian, Lingua 119, 102-127.

Skopeteas, Stavros, Ines Fiedler, Sam Hellmuth, Anne Schwarz, Ruben Stoel, Gisbert Fanselow, Caroline Féry, and Manfred Krifka 2006. Questionnaire on Information Structure (QUIS). Interdisciplinary Studies on Information Structure (ISIS) 4. Universitätsverlag Potsdam, Germany. 
Skopeteas, Stavros and Elisabeth Verhoeven 2005, Postverbal argument order in Yucatec Maya, Sprachtypologie und Universalienforschung 53.1, 71-79.

Speyer, Augustin 2007, Die Bedeutung der Centering Theory für Fragen der Vorfeldbesetzung im Deutschen. Zeitschrift für Sprachwissenschaft 26: 83 - 115.

Temürcü, Ceyhan 2001, Word order variations in Turkish: Evidence from binding and scope. Ph.D. dissertation, Middle East Technical University, Ankara.

Tomlin, Russel 1995, Focal attention, voice, and word order: an experimental, cross-linguistic study. In: Downing, Pamela and Michael Noonan (eds.), Word order in discourse. Amsterdam/Philadelphia: Benjamins, 517-554.

Weber, A. \& Müller, K. 2004. Word order variation in German main clauses: A corpus analysis. Proceedings of the 20th International conference on Computational Linguistics. Geneva, Italy; 7177.

Warburton, Irene 1975, The passive in English and Greek. In: Abraham, Werner (ed.), Foundations of language, International journal of language and philosophy. Boston: Reidel, 563-578.

Xu, Liejiong 2006, Topicalization in Asian languages. In: Everaert, Martin and Henk van Riemsdijk (eds.), The Blackwell companion to syntax, Vol. V. Oxford: Blackwell, 137-174. 